\title{
Case formulations in mentalization-based group therapy
}

\author{
Sigmund Karterud
}

The Norwegian Institute for Mentalization, Bergen, Norway

\begin{abstract}
Ideally, the assessment phase of patients who are referred to mentalization-based treatment (MBT) should conclude with a mentalization-based case formulation. The structure and content of such case formulations are described. Their aim are: i) to enhance treatment alliance and ii) to provide some structure to the treatment process through suggesting privileged themes related to emotions, relational patterns and mentalizing. MBT is a conjoint kind of psychotherapy, integrating individual and group therapies. Case formulations has belonged to the tradition of individual psychotherapy, while being mostly ignored by group therapists. The question is: are case formulations also relevant for group psychotherapy? How can they be properly introduced while not disturbing the group processes? The theme is discussed through a clinical vignette that illuminates typical therapeutic challenges in dynamic group psychotherapy with borderline patients. The author concludes with some suggestions for clinical structure, process and research.
\end{abstract}

Key words: Mentalization-based treatment; Borderline personality disorder; Case formulations; Group therapy.

\section{Introduction}

Mentalization-based treatment (MBT) is well established as an efficient treatment for borderline personality disorder (BPD) (Bales et al., 2012; Bateman \& Fonagy, 1999, 2009; Bateman, O’Connell, Lorenzini, Gardner, \& Fonagy, 2016; Kvarstein et al., 2015).

$\mathrm{BPD}$ is a heterogenous category, including patients at different levels of personality functioning and with different personality profiles. Recent research indicates that MBT is particularly well suited for the most severe part of the BPD

\footnotetext{
Correspondence: Sigmund Karterud, The Norwegian Institute for Mentalization, Svartediksveien 6a, 5009 Bergen, Norway.

Tel.: +47.97095144.

E-mail: wkarteru@online.no

Citation: Karterud, S. (2018). Case formulations in mentalizationbased group therapy. Research in Psychotherapy: Psychopathology, Process and Outcome, 21(3), 132-136. doi: 10.4081/ripppo. 2018.318

Conflict of interest: the author declares no potential conflict of interest.

Funding: none.

Received for publication: 10 July 2018.

Revision received: 10 September 2018.

Accepted for publication: 4 October 2018.

This work is licensed under a Creative Commons Attribution NonCommercial 4.0 License (CC BY-NC 4.0).

CCopyright S. Karterud, 2018

Licensee PAGEPress, Italy

Research in Psychotherapy:

Psychopathology, Process and Outcome 2018; 21:132-136

doi:10.4081/ripppo.2018.318
}

spectrum, i.e. for patients who really are hard to reach. In two studies, MBT was shown to uphold its therapeutic effect also among the most severe patients, while the results of the control conditions (clinical management and psychodynamic therapy) for these patients were meager (Bateman \& Fonagy, 2013; Kvarstein et al., 2018).

It is assumed that the totality of the treatment package (Bateman \& Fonagy, 2016) is important for this surplus effect of MBT for severely disturbed patients: The assessment procedures, the case formulation, the crisis plan, the MBT manuals, the psychoeducational component, the conjoint individual-group therapy format, the team approach, the collaboration with other instances within the mental health service, e.g. acute psychiatric wards, and the video-based team supervision. When organizing treatment according to these principles, it is possible to achieve effect sizes that are twice the more usual range in psychotherapy, e.g. around 1.6 instead of the traditional EZ of 0.7-0.8 (Kvarstein et al., 2015). However, there are still space for improvements. One such element is the mentalization-based case formulation and in particular its usage in the group therapy component of MBT. That is the topic of this article.

\section{Mentalization-based case formulations}

The major schools of psychotherapy have increasingly emphasized the importance of case formulations (Eells, 2015). Case formulations are believed to sharpen the conceptualization of the particular patient's dynamics in accordance to the therapeutic theory in question and thus sharpening the therapeutic focus, enhance patient-therapist cooperation and prevent dropout. There is no agreed upon standard for constructing case formulations since 
personality theories, assumed mechanisms of pathology and mechanisms of change, differ between schools of psychotherapy. However, two broad trends can be identified. The one trend is where the therapist expert formulates a thesis about supposed unconscious conflicts in the patient, a thesis that is delivered to the patient, gradually as part of the therapeutic process. The Core Conflictual Relationship Theme is a prototype of this approach (Luborsky \& Barrett, 2017). The other trend concerns case formulations that are formulated in cooperation with the patient him/herself. Mentalization-based case formulations belongs to this second approach (Karterud \& Kongerslev, [in press]). The co-construction with the patient is a most important premise: The formulation should be written in plain language and adjusted to the mentalization level of the patient. It might be very short and simple (Bateman, 2011) or more elaborate and sophisticated (Karterud \& Kongerslev, [in press]). There is thus no correct way of constructing a mentalization-based case formulation. However, it should preferably contain some themes that typically burdens patients with borderline PD. On the temperament side it concerns hypersensitivity for separation distress, bordering at feelings of total loss, meaninglessness and desperation as well as a low trigger level for rage (Gunderson \& Lyons-Ruth, 2008; Karterud et al., 2016). Separation distress and rage are the two primary emotion vulnerabilities of BPD (Karterud et al., 2016). Low trigger levels are combined with high intensity when aroused, and there are problems with downregulation. However, a difficult temperament does not alone yield a borderline personality. The temperamental disposition should be exaggerated by negative attachment experiences (Weijers et al., 2017) and being precipitated as an overinvolved or disorganized attachment pattern. And furthermore, this combination, the difficult temperament being handled by contradictory or confusing parental attachment strategies, should result in mentalizing deficiencies such as problems of making sense of own experiences (identity problems) and distorted interpretations of others.

The case formulation should organize its narrative around these personality constituents: Temperament/primary emotions, attachment and mentalization/self-consciousness (TAM-theory) (Karterud, 2017; Karterud \& Kongerslev, [in press]). By this way of constructing the case formulation, the therapist is actually suggesting to the patient: Look here, major issues of your life can be regarded in this way, there seems to be some connections here, should we take this as our starting hypothesis and explore its implications? The kind of implications which should find its place in the case formulation, is the current life consequences of temperamental problems, the interpersonal difficulties that come with insecure attachment and the problems due to poor mentalizing, e.g. habitual misinterpretation of self and others as well as acute breakdowns of mentalizing capability. In addition, the therapist may suggest some transference tracers, e.g. how the interpersonal problems of the patient might manifest themselves in relation to the therapeutic constituents, in particular in the relation to the individual therapist and the groups.

\section{Socializing the patient to the treatment model}

The case formulation is part of a broader strategy for socializing the patient to this particular type of treatment. It offers a frame of reference, a certain way of understanding personality problems and some broad principles for how to approach these problems, in particular the mentalizing or not-knowing stance. This frame of reference is explicated in the mentalization-based psychoeducational group (Karterud \& Bateman, 2011b). During this 12 weeks course, during the initial phase of treatment, patients learn basics about mentalizing, mentalizing failures, attachment, attachment patterns, anxiety and attachment, depression and attachment, evolution and primary emotions, borderline personality disorder and the principles of MBT. Patients are given home lessons and the sharing of personal experiences provide the learning process with personal meaning. Patients need to own their case formulation during the first stage of treatment. Although it is a co-operative product, in the sense that patients themselves can suggest themes and formulations, it is clear that the therapist is the main author of structure and content. However, the narrative should gradually become the property of the patient. It need not be the original formulation, which might be partially incorrect, one-sided or missing crucial elements. Case formulations should be revised as the treatment process evolves. However, the essence of it, when altered and acknowledged by the patient him/herself, should be internalized.

\section{Case formulation and group therapy}

Traditionally, case formulations are constructed by the individual therapist, assisted by his/her supervisor and the MBT team, although the patient has the final word. Manuals and guidelines for MBT assign the responsibility to the individual therapist to ensure that the therapeutic process relates to the case formulation (Bateman \& Fonagy, 2016; Karterud \& Bateman, 2010). The roles of the groups and the group therapists are less explicated. The reasons are to be found in the roots of mentalization-based group therapy (MBT-G). MBT-G belongs to the family of psychodynamic group therapies that adheres to psychotherapy through the group process (Karterud, 2015). Psychodynamic group therapists are very cautious at introducing elements in therapeutic groups that would disturb the here-and-now group process, such as e.g. psychoeducation, exercises and home lessons. However, the structure of MBT-G has been altered since its inception (Fonagy, Campbell \& Bateman, 2017; Karterud, 
2015; Karterud \& Bateman, 2011a). Its modern version allows for more structure and group therapist authority in concert with long sequences of spontaneous group interaction. The key ingredient is a structure of turn-taking where each session contains the exploration of intriguing interpersonal events of 2-3 patients where the other group members partake as responsible peers. With such a structure, case formulations might also find their place in dynamic group therapy. I would add that case formulations might become a most useful tool for therapeutic groups with severe personality disorders which constantly run the risk of deteriorating into chaos or a nonproductive pseudomentalizing mode. In the following I will discuss some experiences from my role as trainer and supervisor in MBT-G which have led us to experiment with different ways of handling case formulation in therapeutic groups.

\section{Clinical experiences and case material}

As a trainer and supervisor in MBT-G, I often encounter group therapists who have trouble with particular patients whom they either do not understand, or do not like, or who do not respond to treatment or who the therapists consider a nuisance for the group. My first response is usually: "Can I see the case formulation"? All too often group therapists respond back with embarrassment, e.g. that unfortunately there is no case formulation, or that it is not finished yet, or that it belongs to the conjoint individual therapist. It has become apparent that although MBT is a kind of treatment that favor case formulations, the culture that group therapists usually are part of, contains some resistance to such remedies. Nevertheless, the very phenomena that case formulations are intended to be a remedy against, flourish in groups with personality disorders, e.g. alliance ruptures which have led the therapeutic course on stray. Typical cases display a chaotic mixture of strong primary emotions, attachment confusion and mentalizing deficits.

The following case illustration is from a MBT group session in a typical Scandinavian MBT program. The group is long-term, slow-open and contains mainly borderline patients. There is conjoint individual therapy. In the opening phase of this group session, patients display some resistance at entering the center stage. However, patient P-1, who had been in the program for nearly one year, saves the day for the group:

P-1: "OK, I can start, so just relax (to patient-2). (Sighs.) Yeah, but what should I start with, kind of? I...I don't know where I should start, because, firstly, each time I speak, or open my mouth inside here, and that has made me angry for a long time, because it turns...it is so much...it is so much that bubbles up, but "we can help you with the group here-and-now", that's how it is. (Shouts). But then, what comes out is irrelevant for my daily life. I feel like I'm pissing, or... not you (to fellow patients), but you, yes you (therapist 1 and 2), in a way you piss on my problems, and that they are not so important because... Everything has to be shortened, cut down in a way, because it is kind of too much and...And it gets dragged out of context, and so on and so on. However, the reason why it breaks down is because there is something here. And then I get so frustrated because... Why do I have to... or, why do we never...eh. Ah! Do you get what I mean?"

P-2: "Yes, I understand what you mean"

P-3: "I also understand what you mean"

It is not so clear if therapist 1 and 2 understand what she means, and not this author either. However, we get that P-1 is deeply frustrated and that there is no alliance here. She doesn't feel that the way the therapists (and the group) work make sense to her. To the contrary, her stuff "gets dragged out of context". P-1 is not only deeply frustrated with the group, everything is shit (later on in the same sequence):

P-1: “...Well...I have...OK...two times last week, no, one time this week and one time the week before, in a way I have thrown the dining table towards the wall, because I was so damned pissed off. I get these kind of rage blows. I hit. And...»

Later in the same sequence. P-1: "I'm just pissed off most of the time and I don't know why. And I have... seriously, I would like to...just leak me on to somebody in a way that would escalate to a fight, so I just could kill somebody, just to get my frustration out. That's what I would like to do, and that's what I'm thinking on, nearly every day..."

Later on, in the same sequence: P-1 is talking about "fucking feelings" in the body, "nowadays it is just like when I broke down and got referred to treatment" and "yesterday I started to cry in front of the other students in my group, just because... everything just collapsed, because I should...I'm so tired, it's so much, and I didn't understand what to do, how I should cope, and then it became all too much, so...(imitating explosion noise), and then I started to cry, and when I get there...that kind of crying, it will not stop, it just goes ... (squeals and hyperventilates). It's idiotic". P-1 tells that she ran out to the toilet in order to recover.

This sequence contains most ingredients of borderline pathology: murderous rage, intolerable separation distress (hopeless and despairing sadness), attachment confusion, profound mentalizing difficulties and it is played out in the transference to the group therapists and the group. A major problem is that the alliance is lost and there is no joint exploration and reflection. It is all despair. In such a situation the supervisor would like to gather all therapists, group and individual, to take a fresh look at the treatment from the start and begin with the case formulation. How was it formulated? Did it contain the most important elements? Was it revised? How come that the patient did not achieve any 
ownership to it? What went wrong? Was it formulated way above the mentalizing level of the patient? Did she subordinate to something that was not real for her, which required pseudomentalizing from her side? When did the first signs of poor alliance surface? How could the experiences of this first part of the treatment be summarized and incorporated in a revised case formulation that might help to get the therapeutic process back on track?

\section{New recommendations for case formulations in groups}

Repeated experiences like the one described above has led to new recommendations for case formulations in groups. In a typically slow-open format, where new patients are added when old ones have terminated, there arise a need, both for the newcomer and for the group as a whole, that the newcomer, at some point of time, tells "the story of her/his life". At her/his very first group meeting, she/he is asked to "say something" about her/himself. Usually this is very cursory since most personality-disordered newcomers are highly fear-activated at their first meeting. However, after a month or two, they have become more customized to the group culture and are able to relate to the group in a more nuanced way. That's the time we now recommend new patients to read their case formulation, worked out in collaboration with the individual therapist, as an introduction to their life story. To read it aloud in a group of strangers has a profound effect on all participants, including the group therapists. The ownership of the case formulation then becomes a matter of acute significance. The patient, while reading it, is confronted with the question for her/himself: The protagonist of this story, is this really me? In all respects? Or do I read a story invented by the therapists that is just fake? The other group members usually nod and confirm and support embarrassing elements, compare with their own case formulation, and use the case formulation as a starting point to ask for more life story details. Using half of the time of a group session for this purpose has shown to be a good investment.

The other recommendation concerns new groups, including time-limited groups, that start out with a psychoeducational mode, and thereafter change format to a dynamic MBT group, e.g. after 5-6 sessions. New MBT programs will often starts this way. Time-limited groups may contain less disturbed patients and need not be part of any MBT program, which means that the group therapists may not have any individual therapists as back-ups. The group therapists are forced to construct the case formulations themselves. A radical approach is then to construct the case formulation based upon i) the referral letter, ii) one, or some few clinical interviews, iii) the patient's personal revelations during the psychoeducational stage, and iv) the patients' own initial formulations of treatment goals. By that procedure, relying very much on what pa- tients actually have told about themselves in the group and the patients' own suggestions in the group, the case formulation seems to be owned by the individual-in-thegroup in a more profound way. When coming to the dynamic MBT group phase, patients are asked, in the same way as described above, to read their case formulation as a starting point for the story of their life.

Both of these strategies are fine candidates for qualitative research. Do they really enhance case formulation ownership? For the individual members and the group as a whole? Do they have any significant impact on treatment course, for the individual and the group as a whole?

\section{Conclusions}

Case formulations are crucial elements of MBT treatment packages. However, they have to a large extent been owned by the conjoint individual therapists and not been fully integrated with the group processes. Probably this has hampered a full exploitation of the potentials of MBT. However, the structure of MBT-G is fully compatible with case formulations being read and discussed in groups. This article may hopefully stimulate such a development and the research which is needed.

\section{References}

Bales, D., van Beek, N., Smits, M., Willemsen, S., Busschbach, J. J., \& Verheul, R. (2012). Treatment outcome of 18-month, day hospital mentalization-based treatment (MBT) in patients with severe borderline personality disorder in the Netherlands. Journal of Personality Disorders, 26(4), 568-582.

Bateman, A. (2011). Commentary on «minding the difficult patient»: mentalizing and the use of formulation in patients with borderline personality disorder comorbid with antisocial personality disorder. Personality \& Mental Health, 5(1), 85-90.

Bateman, A., \& Fonagy, P. (1999). Effectiveness of partial hospitalization in the treatment of borderline personality disorder: a randomized controlled trial. American Journal of Psychiatry, 156(10), 1563-1569.

Bateman, A., \& Fonagy, P. (2009). Randomized controlled trial of outpatient mentalization-based treatment versus structured clinical management for borderline personality disorder. American Journal of Psychiatry, 166(12), 1355-1364.

Bateman, A., \& Fonagy, P. (2013). Impact of clinical severity on outcomes of mentalisation-based treatment for borderline personality disorder. British Journal of Psychiatry, 203(3), 221-227.

Bateman, A., \& Fonagy, P. (2016). Mentalization-based treatment for personality disorders. Oxford, GB: Oxford University Press.

Bateman, A., O’Connell, J., Lorenzini, N., Gardner, T., \& Fonagy, P. (2016). A randomised controlled trial of mentalizationbased treatment versus structured clinical management for patients with comorbid borderline personality disorder and antisocial personality disorder. BMC Psychiatry, 16, 304.

Eells, T. D. (2015). Psychotherapy case formulation. Washington, DC: American Psychology Association Books. 
Fonagy, P., Campbell, C., \& Bateman, A. (2017). Mentalizing, attachment, and epistemic trust in group therapy. International Journal of Group Psychotherapy, 67(2), 176-201.

Gunderson, J. G., \& Lyons-Ruth, K. (2008). BPD's interpersonal hypersensitivity phenotype: a gene-environmental-developmental model. Journal of Personality Disorders, 22(1), 22-41.

Karterud, S. (2015). Mentalization-based group therapy (MBT$G)$. A theoretical, clinical and research manual. London, UK: Oxford University Press.

Karterud, S. (2017). Personlighet. Oslo, NO: Gyldendal Akademisk.

Karterud, S., \& Bateman, A. (2010). Manual for mentaliseringsbasert terapi (MBT) og MBT vurderingsskala. Versjon individualterapi. Oslo, NO: Gyldendal Akademisk.

Karterud, S., \& Bateman, A. (2011a). Group therapy techniques. In P. Fonagy, A. Bateman (eds). Mentalizing in mental health practice. Washington DC: American Psychiatric Press.

Karterud, S., \& Bateman, A. (2011b). Manual for mentaliseringsbasert psykoedukativ gruppeterapi. Oslo, NO: Gyldendal Akademisk.

Karterud, S., \& Kongerslev, M. Case formulations in mentalization-based treatment (MBT) for patients with borderline personality disorder. In U. Kramer (ed.). Case formulations for personality disorders: tailoring psychotherapy to the individual client. Cambridge, MA: Elsevier; (in press).
Karterud, S., Pedersen, G., Johansen, M., Wilberg, T., Davis, K., \& Panksepp, J. (2016). Primary emotional traits in patients with personality disorders. Personality \& Mental Health, 10(4), 261-273.

Kvarstein, E. H., Pedersen, G., Folmo, E., Urnes, Ø., Johansen, M. S., \& Hummelen, B. (2018). Mentalization-based treatment or psychodynamic treatment programmes for patients with borderline personality disorder-the impact of clinical severity. Psychology and Psychotherapy: Theory, Research and Practice [Epub Ahead of print]. doi: 10.1111/papt.12179

Kvarstein, E. H., Pedersen, G., Urnes, O., Hummelen, B., Wilberg, T., \& Karterud, S. (2015). Changing from a traditional psychodynamic treatment programme to mentalization-based treatment for patients with borderline personality disorder - does it make a difference? Psychology and Psychotherapy, 88(1), 71-86.

Luborsky, L., \& Barrett, M. S. (2017). The core conflictual relationship theme: a basic case formulation method. In T. D. Eells (ed.) Handbook of psychotherapy case formulations. (pp. 105-135). New York: Guilford Press.

Weijers, J., Fonagy, P., Eurelings-Bontekoe, E., Termorshuizen, F., Viechtbauer, W., \& Selten, J.P. (2017). Mentalizing impairment as a mediator between reported childhood abuse and outcome in nonaffective psychotic disorder. Psychiatry Research, 259, 463-469. 